\title{
Erratum to: Surgical Treatment of Renal Cell Cancer Liver Metastases: A Population-Based Study
}

\author{
Anthony T. Ruys, MD ${ }^{1}$, Pieter J. Tanis, $\mathrm{MD}^{\mathbf{1}}$, Iris D. Nagtegaal, $\mathrm{MD}^{2}$, Peter van Duijvendijk, $\mathrm{MD}^{\mathbf{3}}$, \\ Cornelis Verhoef, $\mathrm{MD}^{4}$, Robert J. Porte, $\mathrm{MD}^{5}$, and Thomas M. van Gulik, MD, $\mathbf{P h D}^{1}$ \\ ${ }^{1}$ Department of Surgery, Academic Medical Centre, University of Amsterdam, Amsterdam, The Netherlands; ${ }^{2}$ Department \\ of Pathology, Radboud University Nijmegen Medical Center, Nijmegen, The Netherlands; ${ }^{3}$ Department of Surgery, \\ Radboud University Nijmegen Medical Center, Nijmegen, The Netherlands; ${ }^{4}$ Department of Surgery, Erasmus MC-Daniel \\ den Hoed Cancer Centre, Rotterdam, The Netherlands; ${ }^{5}$ Department of Surgery, University Medical Centre Groningen, \\ Groningen, The Netherlands
}

ERRATUM TO: ANN SURG ONCOL (2011) 18:1932-1938

DOI 10.1245/S10434-010-1526-X

Iris D. Nagtegaal appeared incorrectly on the original publication of this article. She appears correctly here.

The online version of the original article can be found under doi:10.1245/s10434-010-1526-x.

(C) Society of Surgical Oncology 2014

Published Online: 18 March 2014

T. M. van Gulik, MD, PhD

e-mail: T.M.vanGulik@amc.uva.nl 